\section{An early champion of women's rights}

In his 1859 book On the Origin of Species, Charles Darwin argues that "all animals and plants have descended from some one prototype". In none of the book's six editions does he refer to this common ancestor as being an animal-like hermaphrodite with male and female gonads, as Kimberly Hamlin suggests in her book on Darwinian feminism, From Eve to Evolution (reviewed in Nature 509, 424; 2014). Hamlin writes, for example, that "the possibility of a hermaphroditic past ... opened up a new world of gendered possibilities".

It was the co-discoverer of natural selection, Alfred Russel Wallace, who was a public advocate of women's rights. As reported in The Times on 11 February 1909, he wrote: "All the human inhabitants of any one country should have equal rights and liberties before the law; women are human beings; therefore they should have votes as well as men."

U. Kutschera Institute of Biology, University of Kassel, Germany. kut@uni-kassel.de

\section{Synthetic biology: missing the point}

Volker ter Meulen warns that if environmental groups and others exaggerate the risks of synthetic biology it could promote over-regulation, which he says happened for genetically modified organisms (Nature $\mathbf{5 0 9}, \mathbf{1 3 5}$; 2014). But the point of supporting synthetic biology is not about making sure that science can go wherever it wants: it is about making the type of society people want to live in.

In the United States, for example, the rapid and uncritical introduction of genetically modified organisms prevented debate on issues such as alternative innovation pathways, and the impact on biodiversity and pest resistance. Many believe that these issues would have been better addressed through earlier and broader public discussion of the uncertainties surrounding transgenic organisms (see S. Jasanoff Designs on Nature Princeton Univ. Press; 2005).

In our view, ter Meulen trivializes the role of social scientists in suggesting that they could help the synthetic-biology debate by finding better ways to communicate what scientists think. He also implies that public concern over such technologies and their governance reflects only a failure to understand the science of risk assessment - but this 'deficit model' of public concerns has long been discredited (see A. Irwin and B. Wynne Misunderstanding Science? Cambridge Univ. Press; 1996).

It is not unknown for scientists themselves to foster exaggeration and uncritical acceptance of claims, or to focus on anticipated benefits rather than on risks. This practice may be at the heart of wider public concerns about responsible innovation (see, for instance, go.nature.com/ zehpdp).

Sam Weiss Evans ${ }^{\star}$ University of California, Berkeley, USA. samuel.evans@berkeley.edu ${ }^{*}$ On behalf of 21 correspondents (see go.nature.com/romzbu for full list).

\section{Synthetic biology: a global approach}

Despite some success in advancing best practices for synthetic biology in ethics, safety, security and the environment, the conversation about a global "tribal gathering" is only just beginning (see Nature 509, 133; 2014).

In 2006, when the field was starting to appreciate the concepts and conditions for success, the Synthetic Biology Engineering Center (Synberc; www.synberc.org) was founded with support from the US National Science Foundation. It consisted of 20 investigators who helped to lay the foundations for synthetic biology at a time when tribalism probably still did us some good.

Synberc is now a singularly diverse tribe. It aims to examine the broad social context of biotechnology research practice through programmes that involve political scientists, legal scholars, ethicists, theologians, industrial practitioners, anthropologists and others, along with its own scientific advisory board.

We call for global expansion of the Synberc model into a more inclusive organization that is committed to advancing responsible scientific and social progress in synthetic biology. The main US funding agencies and their counterparts worldwide need to join with academics, industrial partners and society to support this long-term, internationally coordinated effort (see also V. ter Meulen Nature 509, 135; 2014).

Jay D. Keasling ${ }^{\star}$ University of California, Berkeley, USA. keasling@berkeley.edu ${ }^{*}$ On behalf of 16 correspondents (see go.nature.com/bp83hqfor full list).

\section{Successes for UK cancer partnership}

Your examples of important hybrid academic-industrial partnerships for drug development come mostly from the United States (Nature 509, 146; 2014). The Institute of Cancer Research in London has long benefited from such hybrid models. When normalized for each faculty member, our income from intellectual property is highest among UK universities and ranked in the top ten relative to US institutions (see go.nature.com/ohyuqj).

Since 2005 we have discovered 17 drug candidates - in several cases with our industry partners — and 7 of these have progressed to phase I/II clinical trials. Our drug abiraterone was approved in the United States and Europe in 2011, and has changed clinical practice for treating advanced prostate cancer (see J. S. de Bono et al. N. Engl. J. Med. 364, 19952005; 2011). Other examples include drugs that target breast, lung and other cancers by inhibiting proteins such as phosphatidylinositol-3-OH kinase (F. I. Raynaud et al. Mol. Cancer Ther. 8, 1725-1738; 2009) and the molecular chaperone HSP90 (S. A. Eccles et al. Cancer Res. 68, 2850-2860; 2008).

These successes are a result of taking early academic risks, combining academic and pharmaceutical expertise, and implementing strong leadership and project management. Other contributing factors include running multiple projects on a competitive scale, establishing long-term financial support and - most important - selecting productive and timely industrial collaborations.

Paul Workman The Institute of Cancer Research, London, UK. paul.workman@icr.ac.uk

\section{Forgotten founder of bibliometrics}

Besides being one of the conceptual inventors of the Internet (P. Ball Nature 509, 425 ; 2014), the Belgian librarian Paul Otlet first coined the term 'bibliometrics'. In his book Traité de Documentation (1934), he called for the foundation of a new field, bibliométrie, which he defined as the measurement of all aspects related to the publication and reading of books and documents.

As an example, Otlet suggested recording how often a particular book or author is read. He noted that mathematics was becoming increasingly important in most scientific fields, including in biology and sociology, and felt that it should be included in library science as well.

Ronald Rousseau KU Leuven, Belgium. ronald.rousseau@kuleuven.be 